\title{
Erratum to: Health Care: A Brave New World
}

\author{
Shelley Morrisette - William D. Oberman • \\ Allison D. Watts $\cdot$ Joseph B. Beck
}

Published online: 13 April 2013

(C) Springer Science+Business Media New York 2013

\section{Erratum to: Health Care Anal DOI 10.1007/s10728-013-0244-5}

In the original version of this paper, unfortunately, there happened to be a mistake in the paragraph "Several studies have compared health... better results or lower costs [7]." under the section "Health Care is NOT a Right?"

The incorrect sentence is: For example, hip and knee replacements are not performed on Canadian and UK citizens after 77 (no matter how healthy).

The correct sentence is: For example, hip and knee replacements in Canada and the UK are prioritized by age such that older citizens are on a long waiting list.

The online version of the original article can be found under doi:10.1007/s10728-013-0244-5.

S. Morrisette · W. D. Oberman · A. D. Watts $(\square) \cdot$ J. B. Beck

Department of Management and Marketing, Shippensburg University, 1871 Old Main Drive,

Grove Hall, Shippensburg, PA 17257-2299, USA

e-mail: adwatts@ship.edu

S. Morrisette

e-mail: shmorr@ship.edu

W. D. Oberman

e-mail: wdober@ship.edu

J. B. Beck

e-mail: jbbeck@ship.edu 